\title{
Faraway, so close: a spatial account of the Conte I government formation in Italy, 2018
}

\author{
Daniela Giannetti ${ }^{1}$ (D), Andrea Pedrazzani² (D) and Luca Pinto ${ }^{1 \star}$ (i) \\ ${ }^{1}$ Department of Political and Social Sciences, University of Bologna, Strada Maggiore 45, Bologna, Italy and ${ }^{2}$ Department of \\ Social and Political Sciences, University of Milan, Via Conservatorio 7, Milano, Italy \\ *Corresponding author. Email: luca.pinto@unibo.it
}

(Received 17 October 2020; revised 10 March 2021; accepted 11 March 2021; first published online 26 April 2021)

\begin{abstract}
The formation of the 'yellow-green' government that took office in Italy after the general election held on 4 March 2018 looked puzzling to many commentators as the two coalition partners - the Five Star Movement and the League - appeared to be quite distant on the left-right continuum. In this article, we argue that despite being widely used in the literature, a unidimensional representation of parties' policy positions on the encompassing left-right scale is inadequate to explain the process of coalition governments' formation. We focus first on coalition outcomes in Italy in the period 2001-18. Our statistical analysis including, among other variables, parties' policy distance on the left-right dimension performs rather well until 2013 but fails to predict the coalition outcome in 2018. To solve the puzzle, we propose a twodimensional spatial account of the Conte I government formation in which the first dimension coincides with the economic left-right and the second one is related to immigration, the European Union issues and social conservatism. We show that the coalition outcome ceases to be poorly understandable once parties' policy positions are measured along these two dimensions, rather than on the general left-right continuum.
\end{abstract}

Key words: coalition; government formation; Italian politics; policy space; populism; spatial analysis

\section{Introduction}

Formal theory of coalition formation predicts that governments are more likely to form when they satisfy a combination of requirements: they control a majority of seats in the parliament - possibly a minimal winning majority containing no unnecessary party - and include partners with similar ideological backgrounds (Laver and Schofield, 1990; Laver, 1998; Martin and Stevenson, 2001). Governing parties are expected to gain control over as many cabinet portfolios as possible and implement policies that are closest to their ideal policy preferences. These predictions are driven by the assumption that parties are rational actors pursuing three major goals: they want to maximize their utility expressed in office payoffs, their influence on policies, and their vote shares, as gaining office and controlling policies are made possible by winning the elections (Müller and Strøm, 1999).

However, quite often governments that actually form in the real world do not follow such predicted pattern. ${ }^{1}$ At first glance, the 'yellow-green' government installed in the aftermath of

\footnotetext{
${ }^{1}$ Martin and Stevenson (2001) provided a comprehensive testing of the implications of formal models of coalition formation. They concluded that about $40 \%$ of the governments that actually formed in Western Europe are predicted by their model, which incorporates several variables highlighted in coalition theory. In replicating the model of Martin and Stevenson on a different selection of cases, Bäck and Dumont (2007) found a predictive rate of $32 \%$.

(c) Società Italiana di Scienza Politica 2021. This is an Open Access article, distributed under the terms of the Creative Commons Attribution licence (http://creativecommons.org/licenses/by/4.0/), which permits unrestricted re-use, distribution, and reproduction in any medium, provided the original work is properly cited.
} 
the Italian general election held on 4 March 2018 is a perfect example of a deviant case from policy-driven models, as it was composed of two parties that apparently had little or nothing to share other than a generic anti-elite populist rhetoric. Despite their differences, at the end of May 2018 - after about 70 days of thrilling negotiations - the Five Star Movement (M5S) and the League (former known as Northern League, LN) reached an agreement to form a government headed by Giuseppe Conte, a lawyer and university professor close to the M5S, but without any significant previous political experience. These two parties, which taken together won more than $50 \%$ of the votes cast, had contested the election by offering two very different and - according to many observers - incompatible policy platforms. The League, which gained support especially in Northern Italy, advocated a policy package that included lower taxes on personal income and protectionist measures against global trade. The M5S, whose electoral success was mostly achieved in Southern Italy, promised an increase in public spending and the start of a new programme that would have awarded generous benefits to the unemployed and low-income workers (Anelli et al., 2018). Differences about economic policy, together with further disagreements concerning other issues such as environmental protection, seemed to push the two parties towards the opposite flanks of the socio-economic left-right spectrum which, according to most studies of coalition formation, is the most salient dimension shaping party competition in Europe (Benoit and Laver, 2006). ${ }^{2}$

The literature on coalition formation analysed deviations between theoretical predictions and real outcomes through in-depth case studies (Bäck and Dumont, 2007). This article follows the same strategy attempting to shed light on the formation of the Conte I government, which appears to be a puzzling case given the very different policy platforms of the League and the M5S. We examine first the process of government formation in Italy in the period 2001-18. This time span encompasses five legislatures and eight bargaining processes over government formation, excluding the one that led to the caretaker cabinet headed by Mario Monti (2011-12). ${ }^{3}$ To identify the factors underlying government formation we use a conditional logistic regression model following the approach introduced in the literature by Martin and Stevenson (2001). Our analysis reveals that the statistical model we use fails to correctly predict the Conte I government formation. Then we investigate the reasons for such a failure by exploring in detail the structure of the party competition in March 2018. Data about parties' policy positions are derived from an original expert survey fielded by the authors following the Benoit and Laver (2006) format. Our analysis shows that the structure of the policy space can be defined by a first dimension related to the economic left-right, and a second dimension related to immigration, attitudes towards the European Union (EU), and social conservatism. This more complex representation, which highlights the salience of a 'demarcation-integration' dimension (Kriesi et al., 2006, 2008), provides further evidence of the changing shape and structure of the Italian policy space following the Great Recession (Giannetti et al., 2017). The outcome of the government formation process following the March 2018 election becomes understandable once parties' policy positions are measured along these two dimensions, rather than on the classic left-right continuum.

By focusing on the Conte I government case, our study contributes to evaluate how general patterns of government formation in Italy have changed due to the rise of anti-establishment parties in the last decade. Moreover, by combining statistical analysis with a focus on a specific

\footnotetext{
${ }^{2}$ Hand-coded textual analysis of party manifestos shows policy divergences between M5S and the League (Valbruzzi, 2018). However, a comprehensive analysis of the reliability and validity of different estimates of Italian parties' policy positions, and how they correlate, is still lacking.

${ }^{3}$ This period covers most of the so called 'Italian Second Republic', when a series of electoral reforms and changes in the identity of relevant players fundamentally altered the policy space of party competition. The consensual political system that was typical of the First Republic (1946-93) was transformed into a majoritarian one characterized by alternating governments (Cotta and Verzichelli, 2007; Zucchini and Pedrazzani, 2021). As the two periods differ in many important respects, we focus on the latter one to better isolate the effects of our variables. For an analysis of government formation during the First Republic see: Curini and Pinto $(2013,2017)$.
} 
election, this work reaffirms the importance of a combined research strategy to improve our understanding of coalition governments' formation. Finally, our analysis enables us to develop a better knowledge of within-country variations in cabinet formation in a way that it is often difficult to achieve in large cross-national studies.

The article proceeds as follows. In the next section, we briefly review the formal models of coalition formation developed in the literature from which we draw the variables that are used in our statistical analysis. In the second section, we describe the data and methods used in this study. In the third section, we perform a regression logistic analysis to test some implications of formal models of coalition formation using Italy 2001-18. In the fourth section, we provide a two-dimensional spatial account of the Conte I government formation. Concluding remarks follow in the final section.

\section{Formal models of coalition formation: a brief review}

Theories of coalition formation can be broadly divided into three sets of models: the officeseeking, the policy-seeking, and the neo-institutionalist ones (for a review see: Laver and Schofield, 1990; Laver, 1998; Martin and Stevenson, 2001). The office-seeking theories elaborated a series of propositions about government formation in multiparty systems mainly concerning coalitions' size. The 'winning' proposition states that only majority cabinets will form, emphasizing the idea that majority status is a core feature of parliamentary government. This means that potential governments are more likely to form if they control a majority of seats in the parliament. The 'minimal winning coalition' (MWC) proposition predicts that only coalitions that do not contain any unnecessary partner to reach a majority will form (von Neumann and Morgenstern, 1944; Riker, 1962). However, given the wide set of outcomes predicted by officeseeking models, scholars proposed more restrictive versions of the minimal winning solution. One of these is the 'bargaining proposition', according to which parties will prefer coalitions including the smallest number of parties to reduce transaction costs (Leiserson, 1966, 1968). It follows that potential governments are more likely to form the fewer the number of parties they contain.

Predictions derived from office-seeking models were often contradicted by the empirical evidence, as many real-world coalitions clearly violate the implications discussed above (for the prediction rates of the various set of theories see: Martin and Stevenson, 2001; Bäck and Dumont, 2007). Consequently, scholars suggested an alternative set of models, assuming that parties are not primarily driven by office-seeking motivations, but by policy concerns. Policy-seeking theories expect that parties with a similar ideological background should form stable coalitions. Consequently, they predict coalitions consisting of adjacent parties or that have the smallest programmatic distance on the left-right continuum (Axelrod, 1970; De Swaan, 1973). As a consequence, potential governments are more likely to form the lower is their ideological range. It is important to point out that policy-driven models rely on a spatial representation of policy preferences typically along a single dimension of ideology (left-right).

A further set of hypotheses proposed in the literature focused on the identity of specific actors that are more likely to enter the government. Austen-Smith and Banks (1988) highlight the prominent position of the largest parliamentary party in the coalition game, which cannot be easily excluded from winning coalitions. Policy-based theories suggest instead that when parties compete on a single ideological dimension, the party controlling the median legislator should have a privileged position in coalition negotiations (Downs, 1957; Black, 1958).

Starting from the 1990s, the neo-institutionalist approach to coalition formation began to emerge as the major one complementing office- and policy-seeking theories. Neo-institutionalist scholars shift the emphasis on different types of norms and institutions structuring the outcome of the coalition formation processes (Strøm et al., 1994). Among these, informal rules such as pre-electoral commitments to govern together have proven to be an important predictor of the coalitions that 
actually form. Due to the importance of credibility for parties and voters, these statements - which are usually public - impose a powerful constraint on coalition bargaining (Golder, 2006; Debus, 2009). Another element affecting coalition bargaining is the existence of a status quo coalition which, under certain conditions, can enjoy a privileged position in the government formation game (Laver and Shepsle, 1996; Martin and Stevenson, 2010). Previous empirical studies adopting a comparative and multivariate research design proved the importance of institutional/behavioural factors in predicting government formation (Martin and Stevenson, 2001). Therefore, we expect that potential governments are more likely to form if they are based on pre-electoral coalitions (PECs) or the more they mirror the incumbent coalition.

Let's underline that different phases of party competition - pre-electoral, electoral, and postelectoral - can be seen as facets of a continuous process. However, spatial models typically focus on one at a time. For example, when looking at electoral competition, institutional or behavioural constraints - which might be considered endogenous products from the perspective of the 'big picture' of party competition - can be treated as fixed in the short-run (Benoit and Laver, 2006). Following this approach, in the next section, we will test the implications of the models summarized above by examining government formation in Italy in the period 2001-2018.

\section{Data and methodology}

To identify the variables affecting government formation in Italy, we adopt the approach made popular by Martin and Stevenson (2001). Firstly, we assume that each government negotiation represents a formation opportunity, in which parties choose a coalition among many possibilities. The number of potential governments that could form depends on the number of parties represented in the parliament. ${ }^{4}$ In general, for $p$ parties, $2^{p}-1$ potential coalitions exist. This leads to a dataset including 8120 potential governments that could have formed in Italy between 2001 and 2018, grouped in eight formation opportunities. ${ }^{5}$

For each potential coalition in the dataset, we identify a series of attributes derived from the office- and policy-driven models summarized in the previous section and a number of variables related to institutional/behavioural constraints. Using the information on the distribution of seats in the lower and upper chambers of the Italian parliament, ${ }^{6}$ we create two dummy variables, coding as one all the alternatives controlling a majority of seats both in the Chamber and the Senate and those that are MWCs in the lower chamber. ${ }^{7}$ Information about the absolute number of parties included in each potential coalition is used to test the bargaining proposition.

To examine policy-based attributes of potential coalitions, we compute for each of them the ideological range as the distance between the left-most and the right-most party on the general left-right scale. As a source of data for parties' policy positions, we use five surveys administered

\footnotetext{
${ }^{4}$ For each formation opportunity, we include all the parliamentary groups represented in the Chamber of Deputies, with the exclusion of the mixed group and those groups that were formed during the legislature for which we do not have any data on policy positions. When possible, members of the mixed group were reallocated to the main party groups according to the party list under which they had ran the election.

${ }^{5} \mathrm{We}$ discard the formation opportunity associated with the negotiation over the caretaker government headed by Mario Monti because it was formed exclusively by technical ministers without any official party affiliation.

${ }^{6}$ The distribution of seats varies for each formation opportunity and reflects the size of parliamentary party groups at the time of the investiture vote in appointing the government.

${ }^{7}$ Maintaining that negotiators aim at controlling both houses of a bicameral parliament, we might assume that they will try to assemble a legislative majority not only in the lower but also in the upper house, especially in a country such as Italy where the government needs to pass an investiture vote in both chambers. This should 'double' all majority considerations that enter the process of coalition formation (Müller et al., 2008: 24). Achieving a double majority is more difficult when the two houses show increasing levels of incongruence, such as those observed in Italy since 2001 (Pedrazzani, 2017). Although the upper chamber plays a direct role in government formation, the lower house is generally regarded as the main bargaining arena over government formation. For this reason, the existence of minimal winning coalitions is investigated here only in relation to the distribution of seats in the lower chamber.
} 
to Italian experts between 2001 and 2018 following the methodology developed by Laver and Hunt (1992) and Benoit and Laver (2006). ${ }^{8}$ One of the main advantages of this technique in comparison to potential alternatives lies in the fact that it provides scores for individual parties even when they contest the elections as members of PECs. This is particularly important for the Italian case, as since 1994 parties compete in pre-electoral alliances which often issue a joint electoral platform. A limitation of our analysis lies in the fact that it is restricted to the time period 2001-18, as expert surveys data collected following the same format are not available before 2001. 9

The survey asked political experts to locate the most significant parties - those obtaining at least $1 \%$ of the popular vote (see Table 2 for the 2018 election) - on nine substantive policy issues by using 20-point scales. ${ }^{10}$ The nine dimensions allow us to measure parties' support for public spending vis-à-vis lower taxes ('Taxes vs. Spending'), state regulation of the market ('Deregulation'), liberal policies on matters such as abortion, gay rights, and euthanasia ('Social'), integration of immigrants ('Immigration'), environmental protection ('Environment'), and territorial decentralization of decision-making ('Decentralization'). The survey also includes three dimensions dealing with parties' positions on specific aspects of European politics: the scope of EU intervention ('EU authority'), its peacekeeping role ('EU neutrality') and the role of the European Parliament and national governments as democratic accountability mechanisms ('EU accountability'). For each of these nine policy dimensions, experts were also asked to locate each party on a scale measuring the importance or salience of the dimension for that party. This scale ranges from ' 1 ' (not important at all) to '20' (very important). Finally, experts were asked to place Italian parties along the encompassing left-right continuum.

A single 'left-right' continuum has been widely used to measure the positions and movements of political parties in Europe and to test spatial models of political competition in a comparative perspective (Laver and Budge, 1992; Gabel and Huber, 2000). ${ }^{11}$ Conceptually, there are two basic approaches to define the left-right divide. The first one specifies a priori the substantive content of the left-right based on theoretical reasoning. Following this approach, for example, the Comparative Manifestos Project RILE (RIght-LEft) scale pre-defines policy categories as being left or right to code party manifestos (Budge et al., 2001). In the second approach, 'the leftright dimension is defined inductively and empirically as the super issue that most constrains parties' positions across a broad range of policies' (Gabel and Huber, 2000: 96). The content of the left-right continuum can consequently be inferred only a posteriori in a given context. According to the expert survey methodology used in this article expert placements of parties on the leftright dimension are derived without specifying in advance what this should mean. ${ }^{12}$

Finally, to assess the impact of institutional/behavioural constraints in structuring government formation, we include two further variables. The first one is a dummy identifying all the potential

\footnotetext{
${ }^{8}$ The expert surveys concerning the 2008, 2013, and 2018 elections were administered by the authors. For data regarding previous elections, we used those collected by Benoit and Laver (2006). Several techniques - such as mass surveys, expert surveys, and content analysis of party manifestos - have been used to estimate party positions (Laver, 2001). More recently, a new area of research has started to apply automated and statistical approaches to scale positions from political 'text as data' (Grimmer and Stewart, 2013).

${ }^{9}$ Curini and Pinto $(2013,2017)$ and Pinto $(2018)$ use legislative speeches delivered in the debates on investiture votes to analyse government formation and termination in Italy during the period 1946-93.

${ }^{10}$ Experts were selected from members of the Italian Political Science Association (SISP). We sent email invitations to 316 experts, 71 of whom completed the questionnaire, with a response rate of about $22.5 \%$.

${ }^{11}$ Despite the fact that a widely understood 'left-right' continuum has been used to measure parties' and voters' ideological positions in the Western political world, a widespread disagreement exists on the conceptual foundations of this dimension and the way to measure it (Benoit and Däubler, 2017).

${ }^{12}$ Previous analyses of party placements on this dimension in a number of Western and European countries have shown that ideological positions on the left-right continuum can be predicted from policy locations on other more specific policy scales included in the survey, and in particular from the economic left-right ('Taxes vs. Spending') and the social conservatism dimension ('Social') (Benoit and Laver, 2006: 132-136).
} 
governments that are based on a PEC; ${ }^{13}$ the second one is a continuous measure of the proportion of parties represented in each potential coalition that were also represented in the previous cabinet (returnability). ${ }^{14}$ Table 1 shows some descriptive statistics for each formation opportunity included in the analysis. In the following section, we present the results of our statistical analysis.

\section{A statistical analysis of government formation in Italy 2001-18}

To examine how the potential coalitions' attributes listed above affect the likelihood of government formation, we rely on a conditional logistic regression. Through this technique, government formation can be modelled as an unordered discrete choice problem where each formation opportunity represents a case, while the set of alternatives is structured by all the potential coalitions of parties that might form a government. Among all these potential coalitions, only one will match the government being actually formed. The results are reported in Figure 1, which plots unstandardized conditional logit coefficients and their 95\% confidence intervals for three models. The first one (M1) includes only the variables resulting from the predictions derived by officeand policy-seeking formal models and uses the full set of potential coalitions (8120). The second one (M2) incorporates the two behavioural constraints on government formation mentioned above. Finally, the third model (M3) replicates the second one, imposing a majority constraint on the set of potential coalitions used for the analysis (i.e. in each formation opportunity only those alternatives holding a majority in the lower chamber are included, for a total of 3911 observations; for more information see Table 1). ${ }^{15}$ The confidence intervals tell us if a covariate increases or decreases in a significant way the likelihood that a potential government will form. When the confidence intervals are both on the right (or on the left) of the zero line, coalitions' attributes positively (or negatively) influence in a statistically significant way the likelihood of government formation.

The first model shows that the coefficients associated to office- and policy-seeking assumptions have the expected effects (see the Appendix for the regression tables). However, most of them are not statistically significant or significant at the $90 \%$ confidence level. The only variable showing a strongly significant coefficient in M1 is the left-right ideological range: potential governments are less likely to form when the ideological distance between partners increases. The second model provides evidence to a number of implications derived from the main theories of government formation. M2 shows that potential governments holding a majority status in both chambers that are MWCs have a higher chance to form. Moreover, potential coalitions are more likely to form if they are based on a pre-electoral agreement. Conversely, the greater the distance between the left-most and the right-most party in a government alternative, the lower its likelihood to become the actual government. Finally, the number of parties and the proportion of incumbent parties in potential coalitions do not exert any significant impact on government formation. When the analysis includes only majority alternatives, just two variables ideological range and pre-electoral commitments - are statistically significant. In short, potential majority governments are more likely to form if they are based on a pre-electoral alliance minimizing the ideological differences among coalition partners.

To assess the predictive performance of formal coalition theory in the Italian case, we generate predicted probabilities from the models sketched above, assuming that the potential government

\footnotetext{
${ }^{13}$ During the 2018 elections, Italian citizens cast their ballot for the parliament under a new electoral system (Chiaramonte and D'Alimonte, 2018). This is the fourth system adopted in Italy since 1994 (Baldini 2011; Chiaramonte, 2015). Despite their differences, all of them create incentives for parties to form pre-electoral alliances to contest the elections.

${ }^{14} \mathrm{We}$ omit to incorporate covariates identifying potential coalitions that include the largest or the median party on the left-right dimension since in the period under observation in Italy all the governments that formed satisfy these two criteria.

${ }^{15}$ Following previous studies, the existence of a majority and all the other measures included in the analysis are investigated only in relation to the lower chamber. It should be noted however that we introduce an important innovation in comparison to previous studies by taking into account whether or not the potential coalition controls a majority of seats also in the Senate.
} 
Table 1. Descriptive statistics

\begin{tabular}{|c|c|c|c|c|c|c|c|c|}
\hline Form. opportunity & $\begin{array}{l}\text { No. potential } \\
\text { coalitions }\end{array}$ & $\begin{array}{c}\% \text { Maj. (lower } \\
\text { chamber) }\end{array}$ & $\begin{array}{l}\% \text { Maj. (both } \\
\text { chambers) }\end{array}$ & $\begin{array}{c}\% \\
\text { MWC }\end{array}$ & $\begin{array}{l}\text { Avg. No. } \\
\text { parties }\end{array}$ & $\begin{array}{l}\text { Avg. } L-R \\
\text { range }\end{array}$ & $\begin{array}{c}\% \\
\text { PEC }\end{array}$ & $\begin{array}{l}\text { Avg. } \\
\text { Return. }\end{array}$ \\
\hline Berlusconi II (2001-05) PE & 1023 & 48.58 & 43.30 & 2.74 & 5.00 & 12.52 & 0.20 & 0.50 \\
\hline Berlusconi III (2005-06) IE & 1023 & 47.02 & 39.49 & 3.52 & 5.00 & 12.52 & 0.00 & 0.50 \\
\hline Prodi II (2006-08) PE & 4095 & 47.59 & 43.64 & 2.93 & 6.00 & 12.57 & 0.04 & 0.50 \\
\hline Berlusconi IV (2008-11) PE & 63 & 47.62 & 44.44 & 9.52 & 3.05 & 5.75 & 3.17 & 0.51 \\
\hline Letta (2013-14) PE & 127 & 48.82 & 38.58 & 4.72 & 3.53 & 10.17 & 1.57 & 0.00 \\
\hline Renzi (2014-16) IE & 511 & 49.90 & 37.57 & 1.57 & 4.51 & 10.92 & 0.00 & 0.50 \\
\hline Gentiloni (2016-18) IE & 1023 & 49.76 & 37.54 & 0.78 & 5.00 & 11.02 & 0.00 & 0.50 \\
\hline Conte I (2018-19) PE & 255 & 50.20 & 50.20 & 1.57 & 4.02 & 10.17 & 0.78 & 0.50 \\
\hline Total & 8120 & 48.17 & 42.06 & 2.66 & 5.41 & 12.09 & 0.12 & 0.49 \\
\hline
\end{tabular}

Note: Formation opportunities are shown in chronological order. PE stands for 'post-electoral'; IE for 'inter-electoral'. Statistics were computed for each formation opportunity using potential coalitions as units of analysis. Pre-electoral coalitions (PECs) were calculated only for post-electoral formation opportunities.

Table 2. Results of the Italian general election of March 2018

\begin{tabular}{llcccrc}
\hline PEC & Party & Vote \% (Chamber) & Vote \% (Senate) & Seat \% (Chamber) & Seats \% (Senate) & Left-right \\
\hline CR & LN & 17.35 & 17.61 & 19.8 & 18.1 & 18.324 \\
CR & FI & 14.00 & 4.43 & 16.5 & 19.1 & 15.268 \\
CR & Fdl & 4.35 & 1.26 & 5.1 & 5.6 & 18.380 \\
CR & Ncl & 1.30 & 19.14 & 0.6 & 0.0 & 12.706 \\
CL & PD & 18.76 & 2.37 & 17.6 & 16.3 & 7.986 \\
CL & E EU & 2.56 & 32.22 & 35.2 & 34.1 & 9.662 \\
- & M5S & 32.68 & 1.28 & 2.2 & 1.3 & 11.516 \\
- & LeU & 3.39 & 0.0 & 0.0 & 4.314 \\
- & PaP & 1.13 & & 0.0 & 1.924 \\
\hline
\end{tabular}

Note: The general left-right dimension ranges from 1 (left) to 20 (right). Experts are asked to locate parties, taking into consideration all aspects of party policy into account. CR: centre-right pre-electoral coalition (PEC); CL: centre-left.

Source: Ministry of Interior (https://elezionistorico.interno.gov.it/).

with the highest predicted probability is the one being actually formed (Martin and Stevenson, 2001; Bäck and Dumont, 2007). If the models correctly predict the outcome of the coalition formation game, the difference between the predicted probability of the actual government and of the potential government with the highest predicted probability (i.e. the predicted government) will be equal to zero. Otherwise, we should obtain a difference higher than zero. Figure 2 illustrates these deviations for the eight formation opportunities included in our analysis.

Figure 2 shows that M1, which excludes behavioural constraints, performs worse than the other models, guessing the right combination of parties only two times out of eight formation opportunities (Berlusconi II and III). The prediction rate - the number of predicted outcomes divided by the total number of formation opportunities included in the analysis - increases in the models M2 and M3. According to M2, the predicted government corresponds to the one that formed in three out of eight formation opportunities - Berlusconi II, Berlusconi III and Berlusconi IV, for which the difference in the predicted choice probability is zero. This means that the prediction rate of M2 is about $38 \%$, which is a figure similar to that reported by other well-known cross-national studies (Martin and Stevenson, 2001). This figure rises to 50\% considering M3, which is able to predict correctly also the Prodi II government. These prediction rates can be considered quite remarkable if we think that real governments are picked up from thousands of potential alternatives.

A careful investigation of the choice probabilities produced by M2 - which is the most complete one - reveals that predicted governments at least in post-election situations tend to correspond to the PEC which minimizes the ideological distance between partners along the left-right dimension, no matter if it is a majority coalition or not. When pre-electoral alliances are not ideologically 


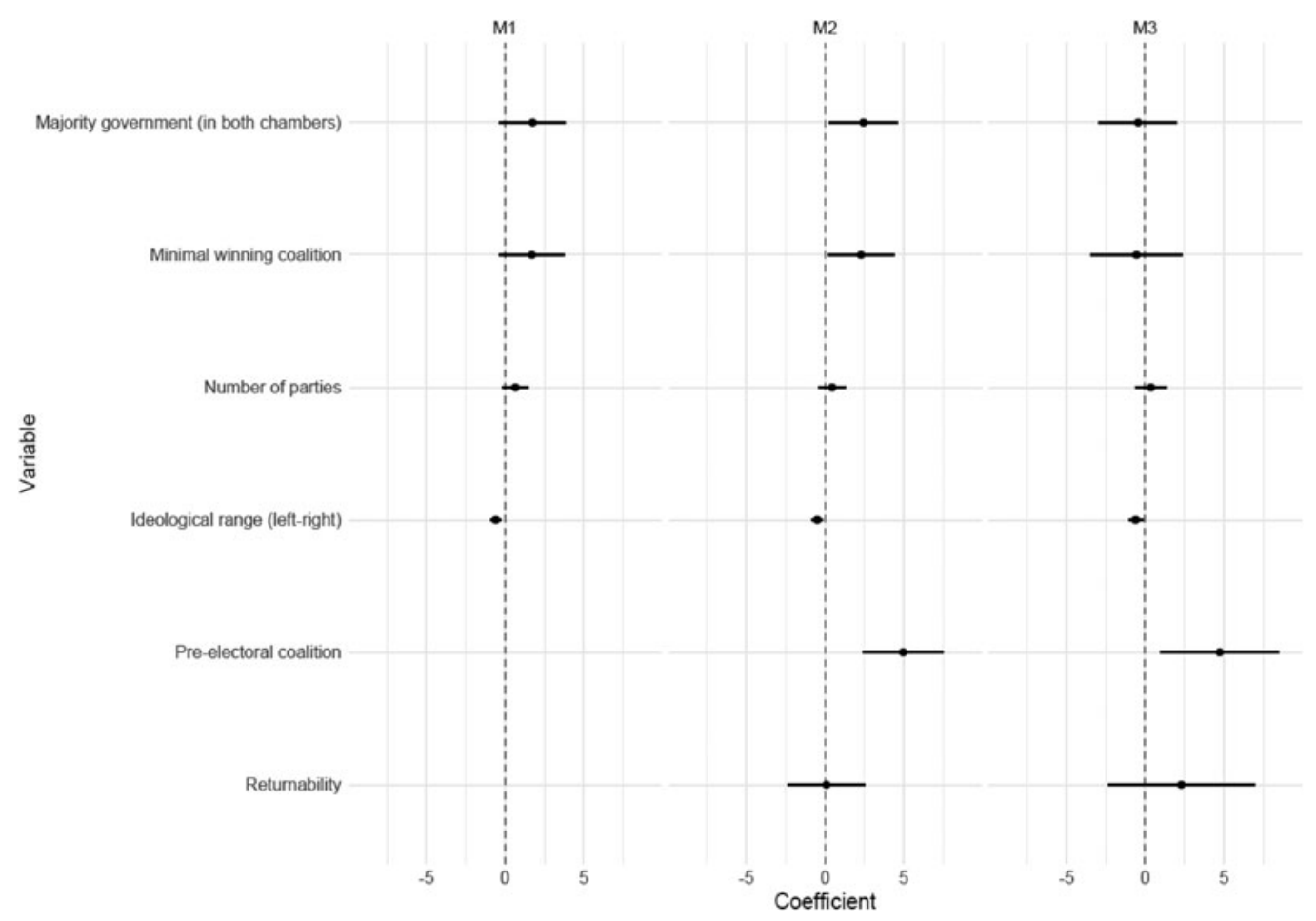

Figure 1. Determinants of government formation, Italy 2001-18.

Note: Parameter estimates are unstandardized conditional logit coefficients with 95\% confidence intervals. M1: Observations (potential governments): 8120 , grouped in eight formation opportunities. Pseudo- $R^{2}$ : 0.23; AIC (Akaike information criterion): 84.418; BIC (Bayesian information criterion): 112.427. M2: Observations (potential governments): 8120 , grouped in eight formation opportunities. Pseudo- $R^{2}$ : 0.40; AIC: 71.853; BIC: 113.867. M2: Observations: 3911, grouped in eight formation opportunities; Pseudo- $R^{2}$ : 0.48; AIC: 58.25; BIC: 95.88.

compact or do not hold a majority both in the lower and upper houses - such as the heterogeneous coalition led by Romano Prodi (2006) which in the Senate could rely on the external support of small parties having no cabinet posts- M2 fails to generate a correct prediction. On the contrary, when a pre-electoral alliance gets a majority in both chambers, M2 produces correct predictions, as in the case of the three cabinets led by Silvio Berlusconi $(2001,2005,2008)$. When imposing the majority constraint, as M3 does, predicted governments usually correspond to the winning PEC resulting from the elections. When none of the pre-electoral alliances obtains a majority of seats - as in the case of the Letta and Conte I governments - the model picks up the combination of parties which minimizes the left-right ideological range. M1 instead fails to predict governments which are based on PECs, such as the Berlusconi IV cabinet. When pre-electoral commitments are not respected by the parties, such as in the formation opportunities which led to the Letta and Conte I governments, M1 produces wrong predictions but less wrong than the other models.

Starting from the Letta government (2013), we observe a worsening in the predictive performance of our models independently from the model specification used. This trend coincides with the entry of the M5S, whose electoral success altered the prevailing pattern of party competition. In 2013 the M5S, contesting its first ever national election, became the most voted party. This resulted in weakening the leverage of the centre-left (CL) and centre-right (CR) PECs which had dominated electoral competition since 1994 (Tronconi, 2015a, 2018). The entry of the M5S also determined a restructuring of the policy space, contributing to the politicising of the EU related issues (Di Virgilio et al., 2015). It has been shown that before 2013 EU-related issues were associated with economic, immigration and social policies. Since 2013 onwards they have 


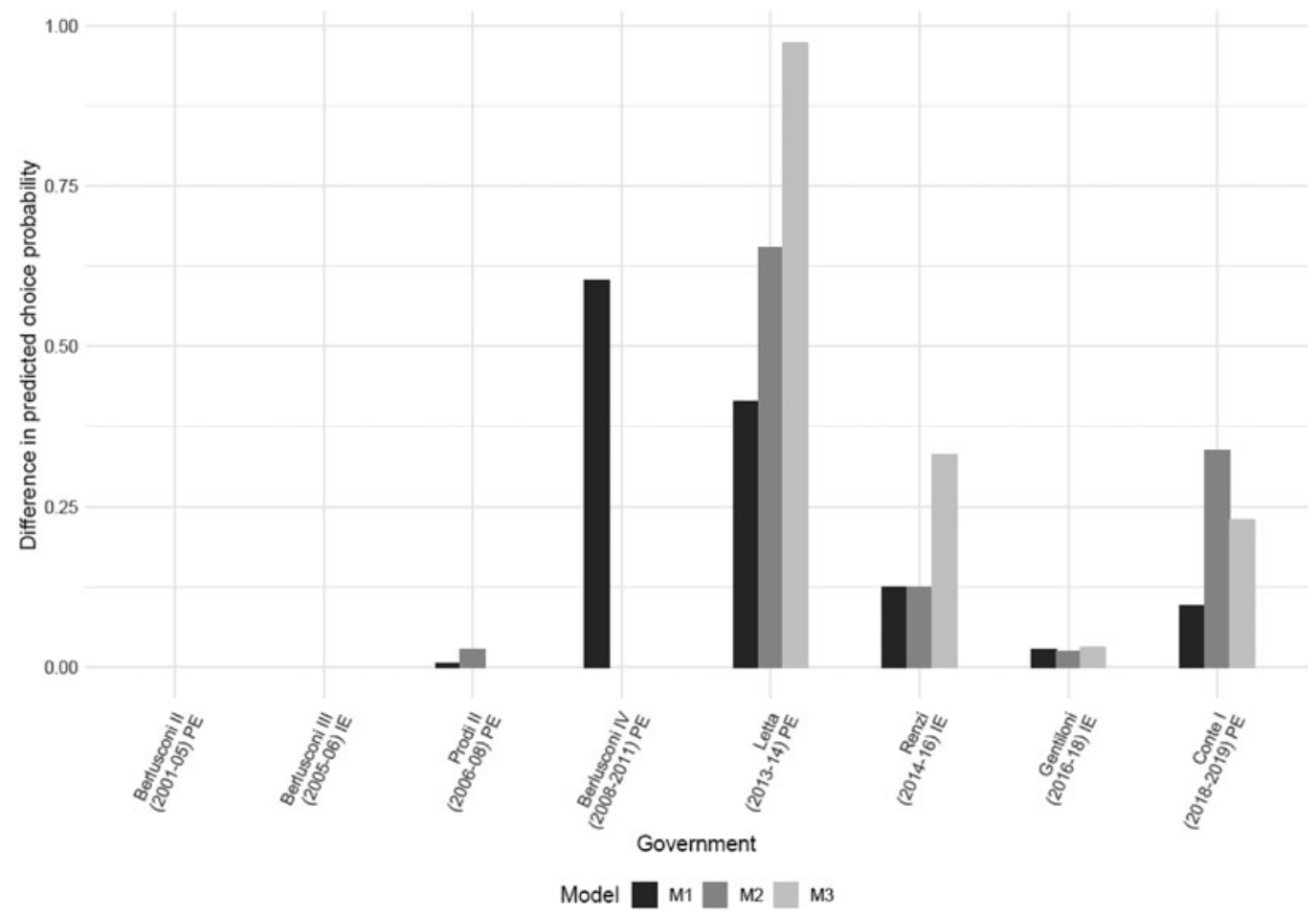

Figure 2. Predictive performance of government formation models, Italy 2001-18.

Note: The $Y$-axis shows the difference between the predicted probability of the actual government and the government with the highest predicted probability (i.e. the predicted government) according to the estimates of the conditional logit models presented in the article. The difference is plotted for each formation opportunity included in our analysis. PE stands for 'post-electoral' governments; IE for 'inter-electoral'. Governments are shown in chronological order.

become more distinctly aligned with a new dimension of political competition tapping pro-/ anti-EU attitudes (Giannetti et al., 2017).

Therefore, our analysis suggests that the inability of the models presented above to correctly predict the governments that formed in Italy from 2013 onwards essentially derives from two interrelated factors. The first one is related to a highly volatile electoral environment (Tronconi, 2015b; Chiaramonte and Emanuele, 2017). The second one is the inadequacy of the general left-right dimension to accurately predict patterns of party competition. The impact of the first factor can be mitigated by excluding from the analysis all the combinations of parties that do not hold a majority in the parliament, as in M3: in this way minority PECs are dropped, and the formation game is limited to those alternatives capable of passing an investiture vote in the parliament. Our results indicate that among these potential governments those minimizing the left-right ideologically range tend to be chosen. As the governments that formed after 2013 consistently deviate from this prediction, there is room to investigate whether or not the general left-right dimension still represents an adequate framework to describe parties' ideological positions in Italy. We explore this issue by focusing on the general election of March 2018 and the formation of the Conte I government.

\section{A spatial account of the Conte I government formation}

On 4 March 2018 Italy voted to elect the Chamber of Deputies and the Senate. Italian citizens cast their ballot under a mixed system in which approximately one-third of the seats are allocated in single-member districts using plurality rule, while two-thirds are assigned through a proportional 
formula. Despite the presence of a plurality tier, the effects of the new electoral rules on the allocation of seats to parties were by and large proportional (Chiaramonte and D'Alimonte, 2018). Votes are allocated to two types of collective political entities: PECs and parties within them. In March 2018, two PECs on the CR and the CL contested the elections. The CR coalition was formed by Go Italy (FI), the League (LN), Brothers of Italy (FdI), and the minor list We are with Italy (NcI). The CL coalition was formed by the Democratic Party (PD), which was the main partner of the incumbent government, More Europe (+EU) and other minor lists, which failed to pass the threshold required by the electoral system to get representation in the parliament. The other 'coalitions' that contested the 2018 election were formed by just one party: the M5S, Free and Equal (LeU), and Power to the People $(\mathrm{PaP}){ }^{16}$

Table 2 reports the electoral results in the two houses of the Italian parliament, together with the number of seats won by each party and their ideological position on the general left-right scale used in the statistical model presented in the previous section. Table 2 shows that none of the two pre-electoral alliances was able to reach a majority in the parliament unless allying with the M5S or forming a 'grand coalition' between the two electoral cartels. Left-right party placements reveal that the League and FdI are the two most far-right parties. PaP and LeU are the two most far-left political groups. The M5S occupies the centre of the left-right continuum, having a position much closer to the PD's one than to other CR parties' positions.

The complexity of the strategic situation emerging from the March 2018 election was reflected in the length of the bargaining process over government formation: 89 days from the election; 69 from the resignation of the incumbent Prime Minister Paolo Gentiloni. The M5S played a prominent role in such a process, negotiating with both the CL and CR parties to form a cabinet. Eventually, after lengthy negotiations, the two 'winners' of the election - the M5S and the League - reached an agreement to form a coalition government headed by the 'neutral' Prime Minister Giuseppe Conte. ${ }^{17}$

The complexity of the bargaining environment that eventually led to the Conte I cabinet is also captured by the models described in the previous section, as they assign very low choice probabilities to the different potential governments that could have formed after the election. Figure 3 plots these probabilities for six plausible majority alternatives, all including the M5S (which is the median party on the left-right dimension). The three models predict different outcomes. However, an element they have in common is that they strongly underestimate the likelihood of an agreement between the far-right League and the centrist M5S. Predicted probabilities indicate as more plausible a coalition between the M5S and the CL PD - which in 2019 actually replaced the League as coalition partner after the fall of the first Conte government - or a combination between the CL pre-electoral alliance (PD and + EU) and the M5S.

To assess the structure of the policy space in the aftermath of the March 2018 general election, we use the expert survey data described in section 'Data and methodology' to identify which policy dimensions appear to be the most important ones. Then, we analyse patterns of correlation between party positions on different policy dimensions to find the underlying axes of political competition.

As noted above, experts were asked to locate parties on a saliency scale, measuring the importance of a particular dimension for that party. Party salience scores enable us to understand which dimensions are the most relevant. We measure the overall importance score for each policy dimension in the 2018 general election by computing, for each issue, the mean of the party-

\footnotetext{
${ }^{16}$ For the sake of mathematical completeness, coalition theory usually takes into account coalitions formed by one party and the 'grand coalition' containing all parties.

${ }^{17}$ Between 2013 and 2018, the M5S increased its vote share from about $25 \%$ to more than $32 \%$. The League moved from about $4 \%$ to $17 \%$. For a comprehensive account of the election see: Istituto Cattaneo (2018); Chiaramonte and De Sio (2019); Ceccarini and Newell (2019). For a review see Pinto (2020).
} 


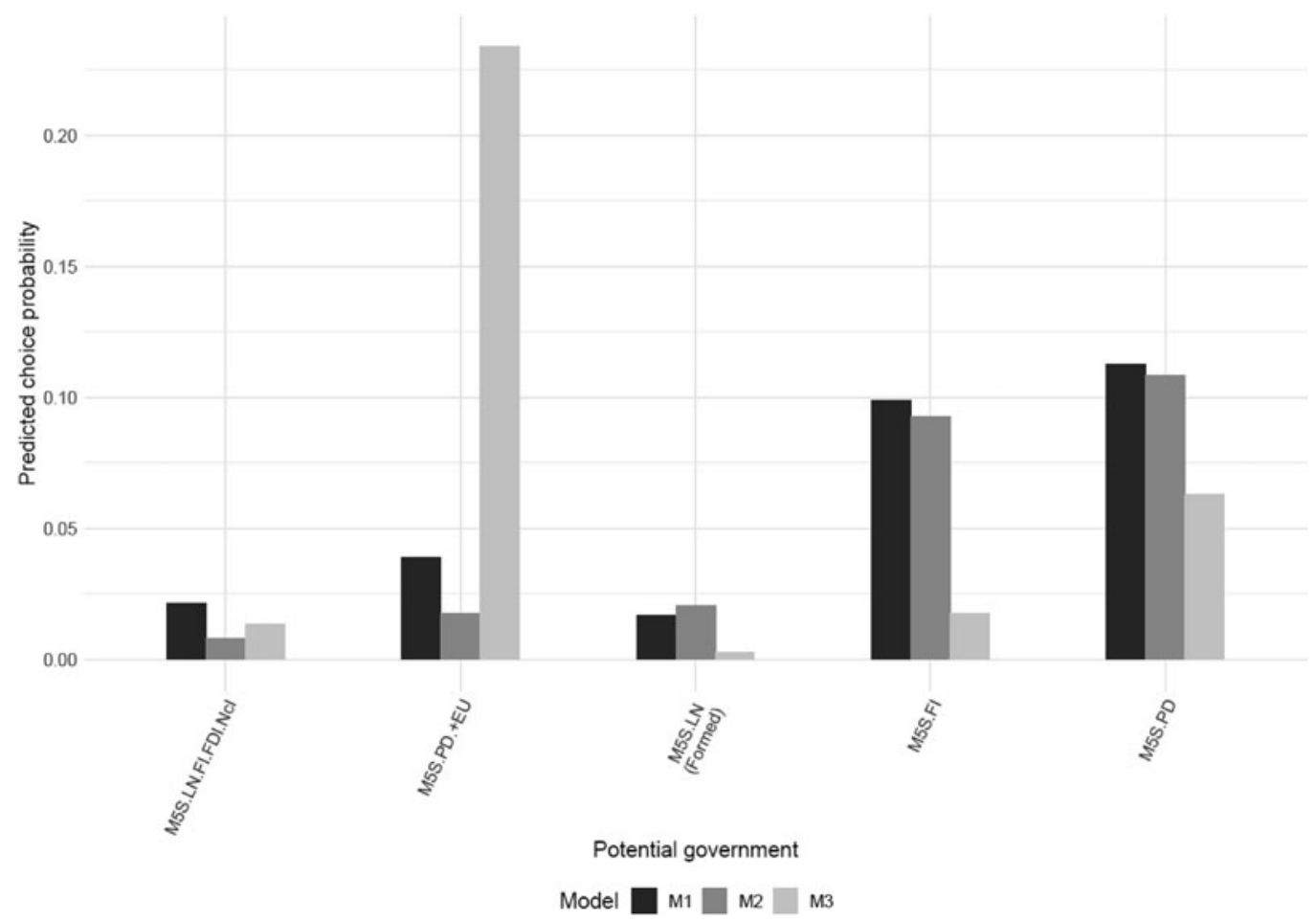

Figure 3. Predictive probabilities of different potential governments following the election of March 2018.

Note: The bars show the predicted probability of different potential governments following the elections of March 2018 according to the estimates of the conditional logit models presented in the article. Alternatives are ordered according to the predictions of M2.

specific salience scores and weighting it by the vote share received by each party. Figure 4 reports the overall importance score of each dimension, as well as its $95 \%$ confidence intervals.

As Figure 4 shows, parties' propensity to increase/reduce the set of policy domains subject to European intervention ('EU authority') was judged by our sample of experts as the most important issue shaping political competition in the Italian election of March 2018. The second most salient dimension is related to 'Immigration', which measures attitudes towards the integration of immigrants. These dimensions received on average higher importance scores than the two dimensions dealing with economic policy ('Taxes vs. Spending' and 'Deregulation'), which are the third and the fourth most important issues. In comparison to past waves of expert surveys fielded in Western European countries - which revealed that economic issues and social policy were most often the top-rated dimensions (Benoit and Laver, 2006) - these data indicate a strong change in the relative weight given by Italian parties to new cultural conflicts linked to the opening up of national borders (Kriesi et al., 2006, 2008). These data also suggest a significant change in comparison to the spatial structure of party competition characterizing Italy in 2013, whereas 'EU authority' and 'Taxes vs. Spending' were the two most important dimensions (Di Virgilio et al., 2015; Giannetti et al., 2017, 2018).

Having identified the most salient policy domains in the period under study, we now turn to providing a more synthetic interpretation of the underlying dimensional structure of Italian party competition in 2018. We assess the dimensionality of political competition in Italy by using exploratory factor analysis (Benoit and Laver, 2006). Factor analysis is a statistical 'data reduction' technique that allows us to describe the variability among a large set of observed variables in terms of a few unobserved underlying factors. Each of the extracted factors can then be 


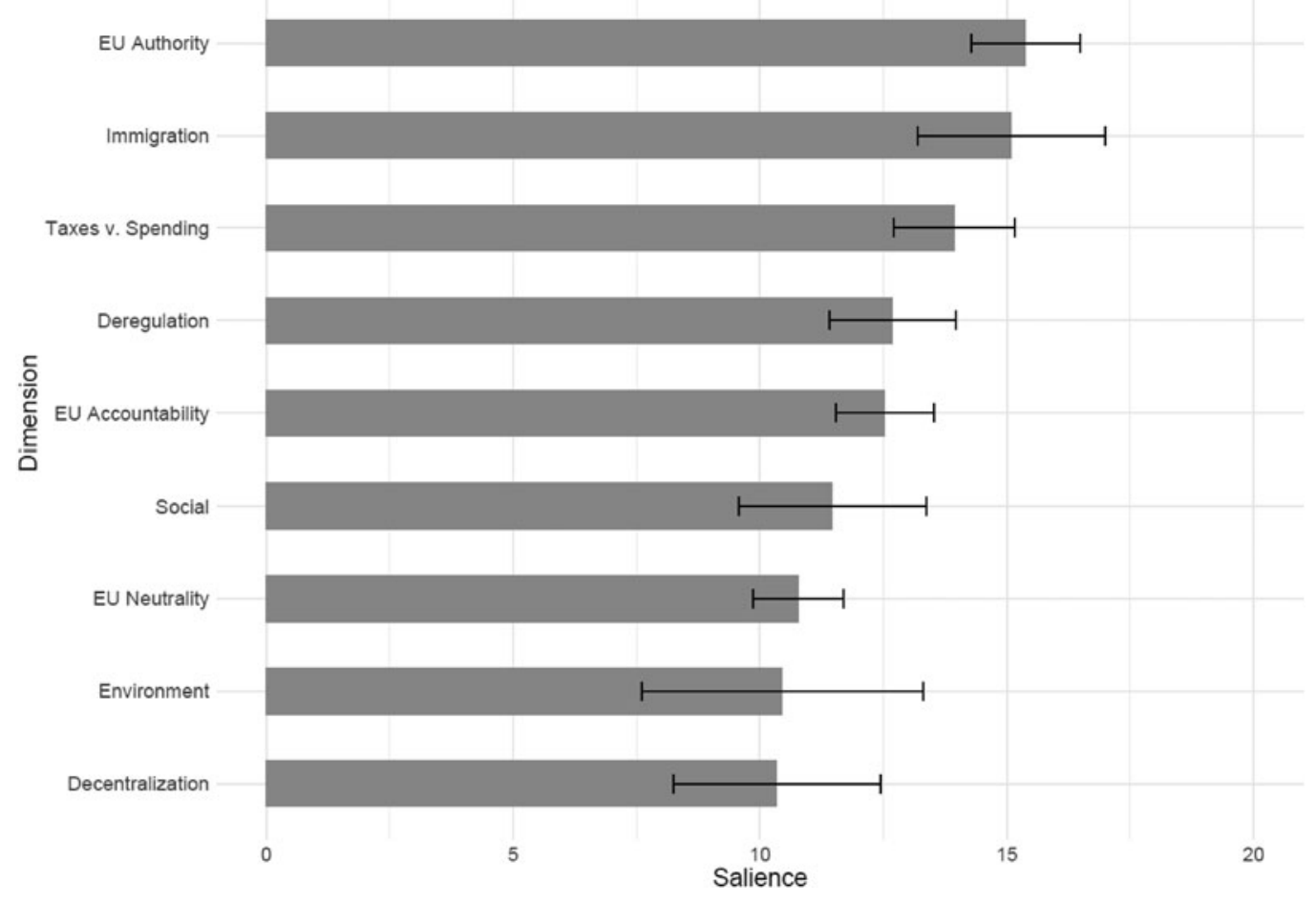

Figure 4. Saliency scores by dimension.

Note: Saliency scores are weighted by parties' vote shares. Error bars represent $95 \%$ confidence intervals.

interpreted substantively by looking at those original variables that 'load' on that factor. The main results of this technique applied to experts' placements of Italian parties' policy positions are illustrated in Table 3, which reports the factor loadings of each policy domain on the latent dimensions for a two-factor configuration. ${ }^{18}$

As reported in Table 3, the first factor emerging from the analysis is related almost exclusively to the economic dimensions, suggesting therefore a traditional economic left-right divide, with the addition of environmental protection related issues. The second factor emerging from the analysis is associated with the dimensions related to immigration, EU authority, EU accountability, EU neutrality, and social conservatism. Thus, this latent factor captures parties' attitudes towards old (cultural liberalism) and new cultural issues, among which European integration and immigration seem to be prominent. Such issues broadly correspond to the new political and cultural axes of competition linked to globalization and the rise of the new populist radical right parties. This factor can be therefore labelled as a 'demarcation-integration' dimension (Kriesi et al., 2006, 2008). Let us underline that social conservatism loads not only on the 'demarcation-integration' factor but also - albeit to a lesser extent - on the first latent factor, which is mainly related to economic issues. In the past decades, party positions on economic issues tended to be highly correlated with those on social issues, as parties having more leftist positions on taxation and deregulation were also those having a more liberal stance about issues such as abortion, gay rights, and euthanasia. Up to 2013, correlation patterns among policy dimensions revealed the relevance of a broad socio-economic left-right, encompassing both economic and social

\footnotetext{
${ }^{18}$ To obtain factors that are more easily interpretable, we used varimax rotation, which is one of the most commonly used rotation options. A scree test suggests that a two-factor configuration best fits our data. Only factors with eigenvalues greater than unity are conventionally interpreted.
} 
Table 3. Dimensional analysis of the Italian policy space, 2018

\begin{tabular}{lrr}
\hline & PA1 & PA2 \\
\hline Taxes vs. Spending & 0.737 & 0.186 \\
Social & 0.512 & 0.621 \\
Deregulation & 0.802 & -0.025 \\
Environment & 0.785 & 0.175 \\
Decentralization & -0.254 & -0.048 \\
Immigration & 0.423 & 0.727 \\
EU authority & 0.090 & 0.826 \\
EU accountability & 0.361 & 0.603 \\
EU neutrality & -0.172 & 0.565 \\
\hline
\end{tabular}

Note: Exploratory factor analysis with a two-factor configuration weighted by the vote share received by each party. $N=639$. Variable loadings higher than 0.5 are in bold.

issues (Giannetti et al., 2017). The configuration of the policy space emerging in 2018 highlights a significant change from the past (see Di Virgilio et al., 2015). In comparison to 2013 the 'demarcation-integration' dimension has gained importance as it has been extensively used by new parties such as the M5S, or by the League under the leadership of Matteo Salvini, as a way to mobilize large portions of the electorate.

Once identified the underlying structure of the policy space in 2018, as a further step in our analysis we estimate parties' positions on the two dimensions of competition highlighted by using factor analysis (i.e. those with eigenvalues higher than one). Figure 5 presents a two-dimensional map of the policy space. where the horizontal axis represents the economic left-right (factor 1) and the vertical axis identifies a 'demarcation-integration' dimension (factor 2). We estimate each parties' preferences using mean regression scores from factor analysis. The figure also shows a division of the policy space into 'regions' occupied by each party - denoted by dashed lines. These portions of the policy space - known as 'Voronoi tessellations' (Benoit and Laver, 2006) define regions closer (in Euclidean terms) to a given party than to any other party. The segments connecting the ideal points of the three main parties involved in the negotiations over government formation - the M5S, the League, and the PD -indicate the Euclidean distance separating those points.

Figure 5 provides a representation of the basic structure of the space within which the PD, the $\mathrm{M} 5 \mathrm{~S}$, and the League are located in three different quadrants of the graph. The PD supports an integration strategy, and it is located on the CL of the economic left-right dimension. Conversely, both the M5S and the League promote a demarcation strategy. However, they are placed on two opposite flanks of the economic left-right continuum: the M5S on the left and the League on the right. ${ }^{19}$ Figure 5 also shows that the positions of the three main parties vary more strongly on the 'demarcation-integration' dimension than on the economic left-right. Therefore, the latent dimension linked to old and new cultural aspects is the most polarizing one.

The configuration of the policy space represented in Figure 5 allows us to understand the outcome of the government formation process which our statistical models failed to predict. The length of the segments connecting the three main parties involved in the bargaining over the Conte I government formation supports a coalition between M5S and the League (Euclidean distance $=1.471)$ compared to a different one formed by M5S and PD (Euclidean distance $=1.732$ ). On the one hand, the M5S-League combination is an MWC in both houses of the Italian parliament; on the other hand, it minimizes the ideological distance (in Euclidean terms) between

\footnotetext{
${ }^{19}$ Contrary to what happens in other countries (see Kriesi et al., 2006, 2008), we do not observe a tripolar structure in which the 'populist' right constitutes a new third pole, but a configuration in which there are two 'populist' poles - one on the right and another one on the left - opposed by a mainstream centre-left party.
} 


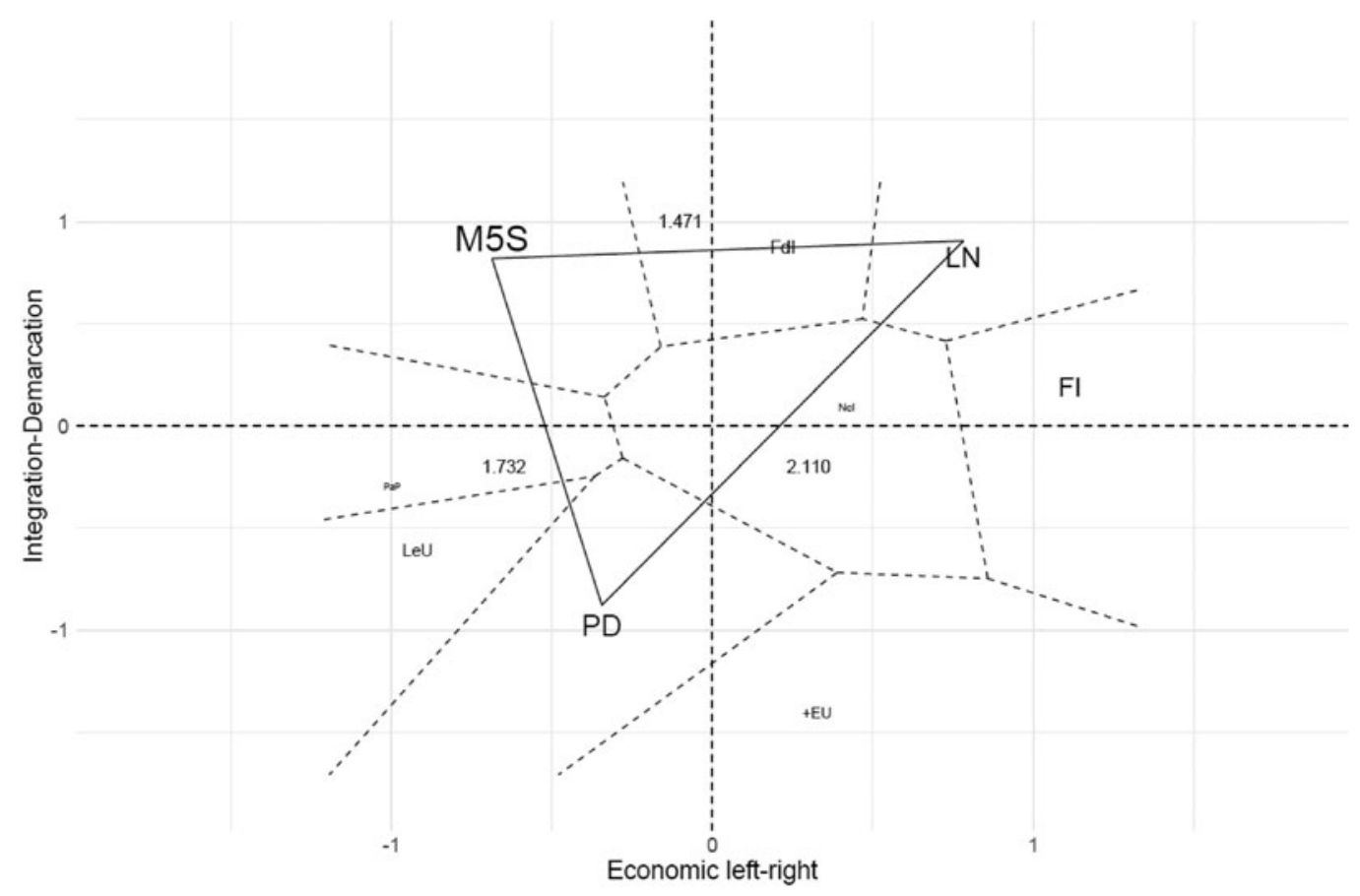

Vote share a 10 a 20 a 30

Figure 5. A two-dimensional map of the Italian policy space, 2018.

Note: Parties' positions are mean regression scores from factor analysis. Label size is proportional to the vote share. Numbers indicate the Euclidean distance between the three parties connected by the segments. Dashed lines denote Voronoi tessellations.

parties in the coalition. Therefore, the coalition between M5S and the League is the most 'rational' combination according to both office-seeking and policy-seeking incentives.

We focused on the Conte I government as a 'deviant' case from the perspective of a monodimensional account of the policy space - that is, the left-right continuum. However, the representation of the policy space depicted in Figure 5 helps us to shed light also on the formation of the subsequent coalition cabinet - led by the same Prime Minister - formed by the M5S and the PD (the Conte II government). ${ }^{20}$ In particular, the figure highlights that none of the main parties involved in negotiations over government formation holds a 'core' position in the policy space (Schofield, 1993). In a two-dimensional policy space, a 'core party', or a 'very strong party' in the terminology of Laver and Shepsle (1996), generates an equilibrium in the government formation game as it can impose its policy preferences to any potential coalition that could form, assuring therefore the stability of the cabinets including it. When the core is empty as it occurs in this case, any majority coalition that forms around a given compromise can be replaced by another majority coalition whose members prefer another policy combination. However, policy cycles do not span all over the entire space but are bound in the area delimited by the triangle identified in Figure 5. Therefore, our analysis suggests that a very likely outcome after the failure of the alliance between the M5S and the League was a government including the PD. ${ }^{21}$ Evidence confirms this prediction.

\footnotetext{
${ }^{20}$ The Conte I government lasted until 5 September 2019. For more information see: Giannetti et al. (2020); Conti et al. (2020).

${ }^{21}$ In this work, we do not examine the set of features affecting government termination. See Laver (2003) for a review of the models that have been developed in the literature.
} 
Returning to the Italian governments analysed in section 'A statistical analysis of government formation in Italy 2001-2018', we performed a regression of left-right scores from party positions on the nine specific issues included in the expert survey. The analysis - whose results are not reported here for the sake of brevity - reveals that the former can be predicted quite well from parties' placements on social, economic, environmental and immigration dimensions. In other words, experts conceive the left-right divide as a kind of 'super-issue' in which parties' positions about the economy interact with attitudes related to a variety of other issues, such as social conservatism, the environment, immigration, and multiculturalism. However, this interpretation of the left-right continuum struggles to describe parties' competition in the 2018 Italian election, which can be accounted for in a more satisfactory way by using a multidimensional representation. To support our argument, we ran again the statistical models described in section 'A statistical analysis of government formation in Italy 2001-2018' including an additional variable measuring potential coalitions' ideological range on the dimension indicated as the most salient ones by expert judgements ('Taxes vs. Spending' in 2001, 2006, and 2008; 'EU Authority' in 2013 and 2018). The inclusion of this supplementary ideological variable in our statistical models generally improves their predictive performance, especially when studying potential governments after the 2013 election. This brings us to restate the conclusion that a multi-dimensional model of the policy space is generally better able to capture the complexity of the process of coalition formation in multi-party systems.

\section{Conclusion}

Although parties' ideological distance on the left-right dimension can help us to understand the process of government formation in Italy between 2001 and 2013, it fails to predict the government that formed after the March 2018 general election. In this work we attempted to show that this deviation of real outcomes from theoretical predictions is mainly a consequence of the inadequacy of a representation based on a single dimension of policy - that is, the general left-right continuum - to describe party competition and it is not due to a failure of the spatial approach to coalition formation.

Using data from an expert survey fielded by the authors in the aftermath of the March 2018 election, we have shown that a two-dimensional representation of the policy space can provide a more convincing explanation of political outcomes. The Conte I government formation looked puzzling to many commentators who judged the M5S and the League as quite distant on the left-right dimension. Relying on the multidimensional approach to coalition formation, we have shown that the two parties supporting the Conte I government were those minimizing the Euclidean distance in a two-dimensional spatial configuration whereas the first dimension is the classic economic left-right and the second dimension - including immigration, EU related issues and social conservatism - can be interpreted as a 'demarcation-integration' continuum. We also suggested that the formation of subsequent Conte II government - supported by the M5S and the PD - was grounded on the same spatial structure.

A number of important implications that might contribute to future research can be drawn from our results. First, our study reveals that the substantive policy dimensions that experts have in mind when defining left and right are mainly associated to socio-economic factors. However, there is evidence that in most countries the economic dimension has been declining in importance while new cultural divisions have become more salient. Researchers should therefore be aware of this discrepancy when designing cross-national studies using parties' positions on a general left-right scale. Second, highlighting the emergence of a new cultural dimension and the related success of two powerful radical parties, our research may contribute to comparative research evaluating the impact of economic crisis and immigration on party competition. There is abundant evidence that a restructuring of the policy space along the lines described in this work characterized not only Italy but many other European countries in the past decades. 
The limitations of our study are inherently related to a framework that relies on policy factors as opposed to valence issues or other non-policy constraints to analyse party competition and coalition formation. According to many scholars, populism has become a crucial factor to understand democratic politics in recent times in many European countries including Italy. Without underestimating the explanatory role of other factors, we believe that our work demonstrates that the spatial approach is an essential tool to study party competition and coalition governments' formation. Another limitation of our study has to do with the fact that it portrays an essentially static picture of the policy space in 2018. This is because in this work we choose to pay attention to a specific instance of government formation deemed particularly important to illustrate the inadequacy of a single dimension of policy to convey a more complex structure of the policy space. Our two-dimensional representation could be easily extended to highlight changes in the structure of the policy space, entry of new parties as well as change in parties' positions to provide a more dynamic account of coalition formation in Italy as well as in other countries.

Funding. The research received no grants from public, commercial, or non-profit funding agency.

Data. The replication dataset is available at http://thedata.harvard.edu/dvn/dv/ipsr-risp.

Acknowledgements. Earlier versions of this article were presented at the ECPR general conference, Hamburg, 22-25 August 2018, and at the SISP conference, Turin, 6-8 September 2018. We thank all participants for discussing the paper, and in particular Lorenzo De Sio for his useful comments. We also thank two anonymous referees for their helpful comments and suggestions.

\section{References}

Anelli M, Colantone I, Pulejo M and Stanig P (2018) Italy just voted for two very different kinds of populism. The Washington Post. Available at https://www.washingtonpost.com/news/monkey-cage/wp/2018/03/28/italy-just-voted-fortwo-very-different-kinds-of-populism/?utm_term=.1e17f8b446be.

Austen-Smith D and Banks J (1988) Elections, coalitions, and legislative outcomes. American Political Science Review 82, 405-22.

Axelrod RM (1970) Conflict of Interest: A Theory of Divergent Goals with Applications to Politics. Chicago: Markham Publishing Company.

Bäck H and Dumont P (2007) Combining large-n and small-n strategies: the way forward in coalition research. West European Politics 30, 467-501.

Baldini G (2011) The different trajectories of Italian electoral reforms. West European Politics 34, 644-63.

Benoit K and Däubler T (2017) Estimating Better Left-Right Positions Through Statistical Scaling of Manual Content Analysis. Working paper.

Benoit K and Laver M (2006) Party Policy in Modern Democracies. London, New York: Routledge.

Black D (1958) The Theory of Committee and Elections. Cambridge: Cambridge University Press.

Budge I, Klingemann H-D, Volkens A, Bara J and Tanenbaum E (2001) Mapping Policy Preferences: Estimates for Parties, Electors, and Governments 1945-1998. Oxford: Oxford University Press.

Ceccarini L and Newell JL (2019) The Italian General Election of 2018 Italy in Uncharted Territory. London: Palgrave.

Chiaramonte A (2015) The unfinished story of electoral reforms in Italy. Contemporary Italian Politics 7, 10-26.

Chiaramonte A and D'Alimonte R (2018) The new Italian electoral system and its effects on strategic coordination and disproportionality. Italian Political Science 13, 8-18.

Chiaramonte A and De Sio L (2019) Il Voto del Cambiamento. Bologna: Il Mulino.

Chiaramonte A and Emanuele V (2017) Party system volatility, regeneration and de-institutionalization in Western Europe (1945-2015). Party Politics 23, 376-88.

Conti N, Pedrazzani A and Russo F (2020) Policy polarisation in Italy: the short and conflictual life of the 'Government of Change' (2018-2019). South European Society and Politics, 1-34.

Cotta M and Verzichelli L (2007) Political Institutions in Italy. Oxford, New York: Oxford University Press.

Curini L and Pinto L (2013) Government formation under the shadow of a core party: the case of the first Italian Republic. Party Politics 19, 502-22.

Curini L and Pinto L (2017) L'arte Di Fare (e Disfare) I Governi: Da De Gasperi a Renzi, 70 Anni Di Politica Italiana. Milano: Egea.

Debus M (2009) Pre-electoral commitments and government formation. Public Choice 138, 45-64.

De Swaan A (1973) Coalition Theories and Cabinet Formations: A Study of Formal Theories of Coalition Formation Applied to Nine European Parliaments After 1918. Amsterdam: Elsevier. 
Di Virgilio A, Giannetti D, Pedrazzani A and Pinto L (2015) Party competition in the 2013 Italian elections: evidence from an expert survey. Government and Opposition 50, 65-89.

Downs A (1957) An Economic Theory of Democracy. New York: Harper.

Gabel MJ and Huber JD (2000) Putting parties in their place: inferring party left-right ideological positions from party manifestos data. American Journal of Political Science 44, 94-103.

Giannetti D, Pedrazzani A and Pinto L (2017) Party system change in Italy: politicising the EU and the rise of eccentric parties. South European Society and Politics 22, 21-42.

Giannetti D, Pedrazzani A and Pinto L (2018) The rising importance of non-economic policy dimensions and the formation of the Conte government in Italy. Italian Political Science 13, 27-44.

Giannetti D, Pinto L and Plescia C (2020) The first conte government: 'Government of Change' or business as usual? Contemporary Italian Politics 12, 182-99.

Golder SN (2006) The Logic of Pre-Electoral Coalition Formation. Columbus: Ohio State University Press.

Grimmer J and Stewart BM (2013) Text as data: the promise and pitfalls of automatic content analysis methods for political texts. Political Analysis 21, 267-97.

Istituto Cattaneo eds. (2018) Il vicolo cieco. Le elezioni del 4 marzo 2018. Bologna: Il Mulino.

Kriesi H, Grande E, Lachat R, Dolezal M, Bornschier S and Frey T (2006) Globalization and the transformation of the National Political Space: Six European Countries Compared. European Journal of Political Research 45, 921-56.

Kriesi H, Grande E, Lachat R, Dolezal M, Bornschier S and Frey T (2008) West European Politics in the Age of Globalization. Cambridge: Cambridge University Press.

Laver M (1998) Models of government formation. Annual Review of Political Science 1, 1-25.

Laver M ed. (2001) Estimating the Policy Position of Political Actors. London: Routledge.

Laver M (2003) Models of government termination. Annual Review of Political Science 6, 23-40.

Laver M and Budge I (1992) Measuring policy distances and modeling coalition formation. In Laver M and Budge I (eds) Party Policy and Government Coalitions. New York: St. Martin's Press, pp. 15-40.

Laver M and Hunt WB (1992) Policy and Party Competition. London: Routledge.

Laver M and Schofield N (1990) Multiparty Government: The Politics of Coalition in Europe. Oxford: Oxford University Press.

Laver M and Shepsle KA (1996) Making and Breaking Governments: Cabinets and Legislatures in Parliamentary Democracies. Cambridge: Cambridge University Press.

Leiserson MA (1966) Coalitions in Politics (PhD thesis). Yale University, USA.

Leiserson MA (1968) Factions and coalitions in one-party Japan: an interpretation based on the theory ofgames. American Political Science Review 62, 770-87.

Martin LW and Stevenson RT (2001) Government formation in parliamentary democracies. American Journal of Political Science 45, 33-50.

Martin LW and Stevenson RT (2010) The conditional impact of incumbency on government formation. American Political Science Review 104, 503-18.

Müller WC and Strøm. K (1999.) Policy, Office, or Votes? How Political Parties in Western Europe Make Hard Decisions. Cambridge: Cambridge University Press.

Müller WC, Bergman T and Strøm K (2008) Coalition theory and cabinet governance. In Strøm K, Müller WC and Bergman T (eds) Cabinets and Coalition Bargaining: The Democratic Life Cycle in Western Europe. Oxford: Oxford University Press, pp. 1-50.

Pedrazzani A (2017) Fare le leggi nella Seconda Repubblica: Come cambia il Parlamento. Milano: Egea

Pinto L (2018) Like leaves in the wind? Economic conditions and government survival in Italy (1946-2015). South European Society and Politics 23, 341-64.

Pinto L (2020) The 2018 Italian general election: a 'new Italy 'or a 'dead end'? Italian Political Science Review 50, $298-303$.

Riker WH (1962) The Theory of Political Coalitions. New Haven: Yale University Press.

Schofield N (1993) Political competition and multiparty coalition governments. European Journal of Political Research 23, 1-33.

Strøm K, Budge I and Laver M (1994) Constraints on cabinet formation in parliamentary democracies. American Journal of Political Science 38, 303-35.

Tronconi F (2015a) Beppe Grillo's Five Star Movement: Organisation, Communication and Ideology. London: Routledge.

Tronconi F (2015b) Bye-bye bipolarism: the 2015 regional elections and the new shape of regional party systems in Italy. South European Society and Politics 20, 553-71.

Tronconi F (2018) The Italian five star movement during the crisis: towards normalisation? South European Society and Politics 23, 163-80.

Valbruzzi M (2018) When populists meet technocrats. The Italian innovation in government formation. Journal of Modern Italian Studies 23, 460-480.

von Neumann J and Morgenstern. O (1944) Theory of Games and Economic Behavior. Princeton: Princeton University Press.

Zucchini F and Pedrazzani A (2021) Italy: Continuous change and continuity in change. In Bäck H, Bergman T and Hellström J (eds) Coalition Governance in Western Europe. Oxford, Oxford University Press. 


\section{Appendix}

Table A1. Determinants of government formation, Italy 2001-18

\begin{tabular}{lccc}
\hline & M1 & M2 & M3 \\
\hline Majority government (in both chambers) & $1.763^{+}$ & $2.441^{\star}$ & -0.455 \\
& $(1.069)$ & $(1.108)$ & $(1.266)$ \\
Minimal winning coalition & 1.723 & $2.284^{\star}$ & -0.557 \\
Number of parties & $(1.049)$ & $(1.077)$ & $(1.481)$ \\
& 0.666 & 0.454 & 0.368 \\
Ideological range (left-right) & $(0.412)$ & $(0.434)$ & $(0.511)$ \\
& $-0.581^{\star *}$ & $-0.495^{\star *}$ & $-0.613^{\star *}$ \\
Pre-electoral coalition & $(0.176)$ & $(0.184)$ & $(0.226)$ \\
& & $4.956^{\star *}$ & $4.731^{\star}$ \\
Returnability & & $(1.290)$ & $(1.916)$ \\
& & 0.094 & 2.297 \\
AIC & & $(1.259)$ & $(2.380)$ \\
BIC & 84.418 & 71.854 & 58.253 \\
Pseudo $R^{2}$ & 112.427 & 113.866 & 0.399 \\
Observations & 0.234 & 8120 & 0.476 \\
\hline
\end{tabular}

Standard errors in parentheses.

${ }^{+} p<0.1,{ }^{\star} p<0.05,{ }^{\star \star} p<0.01$.

Cite this article: Giannetti D, Pedrazzani A, Pinto L (2022). Faraway, so close: a spatial account of the Conte I government formation in Italy, 2018. Italian Political Science Review/Rivista Italiana di Scienza Politica 52, 83-100. https://doi.org/ 10.1017/ipo.2021.11 